\title{
Advanced abdominal pregnancy with a healthy newborn: a rare case report
}

\author{
Kiran Trivedi*, Lata Singh
}

Department of Obstetrics and Gynecology, Rajendra Institute of Medical Sciences, Ranchi, Jharkhand, India

Received: 08 September 2016

Accepted: 12 September 2016

\section{*Correspondence:}

Dr. Kiran Trivedi,

E-mail: trivedikiran2011@gmail.com

Copyright: () the author(s), publisher and licensee Medip Academy. This is an open-access article distributed under the terms of the Creative Commons Attribution Non-Commercial License, which permits unrestricted non-commercial use, distribution, and reproduction in any medium, provided the original work is properly cited.

\begin{abstract}
Abdominal pregnancy is a rare form of extra-uterine gestation where implantation occurs within peritoneal cavity, but outside fallopian tubes and ovaries. Abdominal pregnancies account for $1 \%$ of ectopic pregnancies. Advanced abdominal pregnancy with healthy fetus, surviving upto term is extremely rare. We report an advanced abdominal pregnancy which was referred from a private hospital as a case of central placenta praevia, severe oligohydramnios with 8 months pregnancy and loss of foetal moment and breech presentation. Intra operatively it was diagnosed as a case of abdominal pregnancy. We delivered a LBW $(2 \mathrm{~kg})$ baby from abdomen. Post-operative period was uneventful and both mother and baby were doing well at the time of discharge.
\end{abstract}

Keywords: Abdominal pregnancy, Advanced abdominal pregnancy, Ectopic pregnancy, Healthy newborn, Oligohydramnios

\section{INTRODUCTION}

Abdominal pregnancy is a rare form of ectopic pregnancy with very high morbidity and mortality for both the mother and the fetus. An abdominal pregnancy is defined as an ectopic pregnancy that implants in the peritoneal cavity. ${ }^{1}$ Ectopic pregnancy represents about $1 \%$ of all pregnancies, with $95 \%$ occurring in the fallopian tube. Abdominal pregnancies represent just about $1 \%$ of ectopic pregnancies. The incidence of abdominal pregnancy in different publications varies and ranges between $1: 10,000$ pregnancies to $1: 30,000$ pregnancies. ${ }^{2,3}$

Viable, advanced abdominal pregnancies are very rare and only a few sporadic cases have been reported in the past 10 to 15 years. ${ }^{4}$

The maternal mortality rate is estimated to be about 5 per 1,000 cases, about seven times the rate for ectopic in general, and about 90 times the rate for a "normal" delivery (1987 US data). ${ }^{5}$
Diagnosis and management can pose some difficulties in low resource centers. High index of suspicion is vital in making prompt diagnosis in such situations.

Abdominal pregnancy can be primary abdominal or secondary abdominal pregnancy. Secondary abdominal pregnancy being much more common than primary abdominal pregnancy. Studdiford has established three criteria for diagnosing primary abdominal pregnancies. ${ }^{6}$

- Normal bilateral fallopian tubes and ovaries.

- The absence of utero-placental fistula.

- Pregnancy related exclusively to the peritoneal surface and young enough to eliminate the possibility of secondary implantation following primary nidation in the tube.

Abdominal pregnancies generally do not get to term, and usually end result is the extraction of a dead fetus. Another challenge for babies from abdominal pregnancy is very high incidence of congenital malformation. The 
reports of fetal malformation is as high as $40 \%$ associated with only $50 \%$ babies upto one week postdelivery.,

Advanced abdominal pregnancy with a healthy viable fetus is therefore an extremely rare condition. We present a case of abdominal pregnancy with a live Low birth weight (LBW) fetus without any congenital malformation.

\section{CASE REPORT}

Our patient was a healthy 20 years old, unbooked, primigravida, without regular ante-natal check-up (ANC). Her first and second trimesters were uneventful. Also, she did not have any ANC during her first and second trimesters. She visited a private nursing home in Giridih, Jharkhand at 8 months gestation; with complain of decreased fetal movements. Ultrasonography was done there, and it was diagnosed as a case of complete placenta praevia with severely diminished liquor and breech presentation. She was given corticosteroids at that centre and referred to our institute, Rajendra Institute of Medical Sciences, Ranchi, for central placenta praevia.

On examination in our institute, her vitals were stable, PR $86 / \mathrm{min}$, regular; BP was $120 / 80 \mathrm{~mm}$ of $\mathrm{Hg}$. She had moderate pallor, chest and cardiovascular examination was unremarkable. Uterus was 34 to 36 weeks size, breech presentation; fetal heart rate was $130-140$ beats per minute and regular. CTG monitoring showed reassuring fetus.

As the patient was complaining of less fetal movements, severe oligohydramnios was present, central placenta praevia with 34 weeks gestation and corticosteroids had already been given, decision for caesarian section was taken.

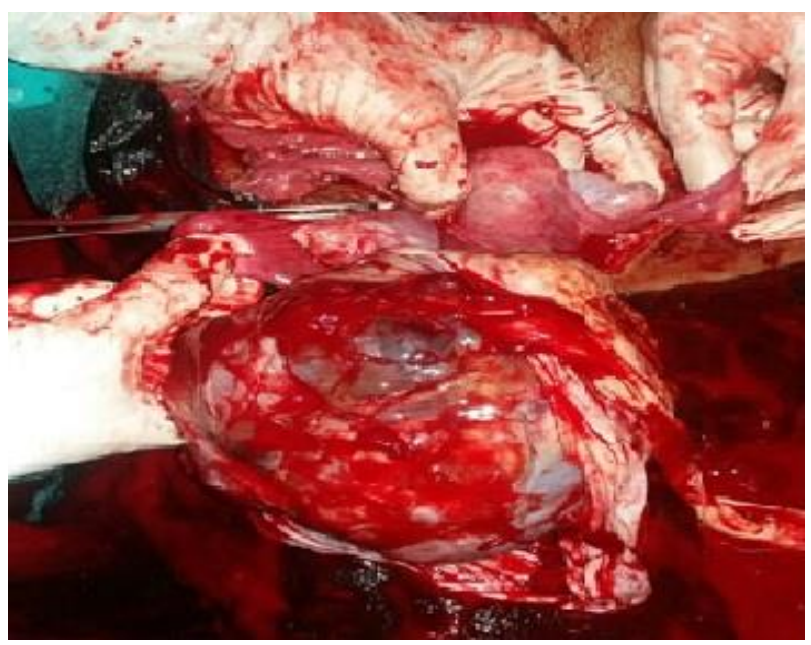

Figure 1: Placenta seen separate from uterus, bilateral tubes and ovaries are normal.

On opening the abdomen, fetus along with placenta was seen lying in the peritoneal cavity. Uterus was slightly bulky, normal looking. Bilateral tube and ovary was normal (Figure 1). No haemoperitoneum was present. Placenta was attached to the pelvic peritoneum, with no connection to the uterus (Figure 2). Liquor was almost nil. We delivered a LBW (2 kg), active, pink and crying baby from upper abdomen. Placenta could be separated with ease from peritoneal surface, except for few bleeders, which were secured with catgut no 1-0. Baby was kept in NICU as it was low birth weight, observed for 24 hours and handed over to the mother on day 2. She was given 1 unit of fresh whole blood. Her post-operative recovery was uneventful. She was discharged on day 8 with her baby.

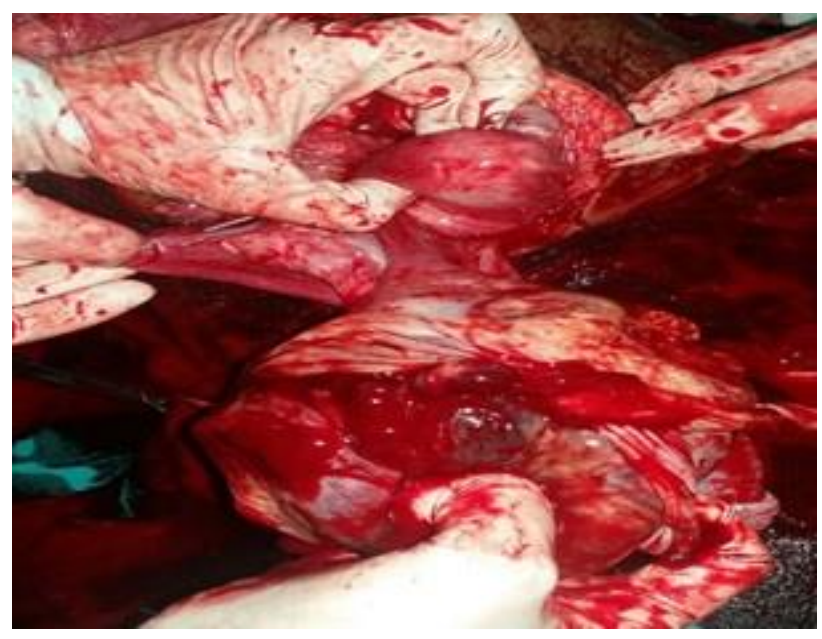

Figure 2: Attachment of placenta to peritoneum seen.

\section{DISCUSSION}

Advanced abdominal pregnancy (AAP) is extremely rare and is defined as a pregnancy going beyond 20 weeks of gestation with a fetus living, or showing signs of having once lived and developed, in the mother's abdominal cavity. ${ }^{7-10}$ There are few reported cases of abdominal pregnancy developing to term with delivery of a live fetus through an abdominal incision. ${ }^{11}$ There is a significant risk of maternal intra-peritoneal hemorrhage with fatal consequences. The overall fetal survival rate remains low. ${ }^{12}$

A high index of suspicion is needed to make a first time diagnosis of abdominal pregnancy. ${ }^{13}$

Diagnosis of AAP is difficult and is made on the basis of history, physical examination and ultrasonography. But, a pre-operative diagnosis is usually missed, more commonly than it is made. Only $45 \%$ of cases are diagnosed preoperatively.

Ultrasonography is an important tool in assessing a suspected advanced abdominal pregnancy. The most frequent and reliable finding includes an empty uterus seen separate from the fetus. ${ }^{14,15}$ Other signs include an ectopic intra-abdominal placenta, pseudo placenta praevia 
appearance, oligohydramnios, lack of myometrial tissue around fetus, fetus and placenta obscured by overlying bowel gas and abnormal fetal presentation.

In our case, severe oligohydramnios, abnormal fetal lie and presentation was present, but was missed. High suspicion of abdominal pregnancy should be kept in mind in order to be able to diagnose AAP. MRI plays an important role in diagnosis, but unfortunately, it is lacking in most parts, especially in peripheral regions of INDIA. In this case, MRI was not done because abdominal pregnancy was not suspected pre operatively.

In our case, bilateral tubes and ovaries were normal and there was no fistulous connection between placenta and uterus. This fulfils two out of the three Studdifords' criteria. In this case, diagnosis was not made in early pregnancy as the patient did not get any ANC done. Third criterion remains unidentified. Patient came to us near term; moreover, condition was diagnosed intra operatively. This may be a case of primary abdominal pregnancy diagnosed late.

As it is a life-threatening condition, pregnancy is usually terminated as soon as the diagnosis of abdominal pregnancy is made. Expectant management may be carried out in selected cases, if it is diagnosed late $>24$ weeks, with careful monitoring of maternal and fetal condition. Expectant management, however, carries a risk of sudden life-threatening intra-abdominal bleeding and a generally poor fetal prognosis. ${ }^{16}$

After delivery of the baby, placental implantation should be carefully assessed. If placenta is adherent, and torrential bleeding is anticipated on separation, cord can be cut short and left as such. Post-operative methotrexate can be given in such cases. However, some argue, that leaving the placenta in situ can result in rapid placental destruction, leading to accumulation of necrotic debris and promotion of bacterial infection. ${ }^{14,17}$

It may be advisable to remove placenta if its blood supply can be secured, if diagnosis is made in early pregnancy or fetal demise is of $>4$ weeks duration.

In our case, placenta was attached to the pelvic peritoneum, which was separated easily. Few bleeders present, were secured.

\section{CONCLUSION}

Abdominal pregnancy is a very rare condition. Moreover, advanced abdominal pregnancy with resultant healthy new born is rarer. Diagnosis of the condition is difficult, especially in advanced pregnancy. High level of suspicion, careful clinical and ultrasound examination is the key to correct diagnosis. MRI and CT scan may be helpful. Bleeding is the single most important life threatening complication for the mother, while, fetal malformation is of the numerous challenges that confronts the newborn. The management depends on overall clinical picture. Prompt surgical intervention with careful evaluation of the placenta before its removal offers the best prognosis.

\section{Funding: No funding sources \\ Conflict of interest: None declared \\ Ethical approval: Not required}

\section{REFERENCES}

1. Stanley JH, Horger EO, Fagan CJ, Andriole JG, Fleischer AC. Sonographic findings in abdominal pregnancy. AJR Am J Roentgenol. 1986;147(5):1043-6.

2. Sapuri M, Klufio C. A case of advanced viable extrauterine pregnancy. PNG Med J. 1997;40:44-7.

3. Atrash HK, Friede A, Hogue CJ. Abdominal pregnancy in the United States: Frequency and maternal mortality. Obstet Gynecol. 1987;69(3 Pt 1):333-7.

4. Studdiford WE. Primary peritoneal pregnancy. Am J Obstet Gynecol. 1942;44:487-91.

5. Teng H, Kumar G, Ramli N. A viable secondary intra-abdominal pregnancy resulting from rupture of uterine scar: role of MRI. Br J Radiol. 2007;80:1346.

6. Kun K, Wong P, Ho M, Tai C. Abdominal pregnancy presenting as a missed abortion at 16 weeks gestation. Hong Kong Med J. 2000;6(4):4257.

7. Crawford JD, Ward JV. Advanced abdominal pregnancy. Obstetrics and Gynecology. 1957;10(5):549-54.

8. Beacham WD, Hernquist WC, Beacham DW, Webster HD. Abdominal pregnancy at Charity Hospital in New Orleans. American J Obstetr Gynecol. 1962;84(10):1257-66.

9. Opare-Addo HS, Deganus S. Advanced abdominal pregnancy: a study of 13 consecutive cases seen in 1993 and 1994 at Komfo Anokye Teaching Hospital, Kumasi, Ghana. African J Reprod Health. 2000;4(1):28-39.

10. Worley KC, Hnat MD, Cunningham FG. Advanced extrauterine pregnancy: diagnostic and therapeutic challenges. American Journal of Obstetrics and Gynecology. 2008;198:297.e1-297.e7.

11. Ludwig M, Kaisi M, Bauer O, Diedrich K. The forgotten child-a case of heterotopic, intra-abdominal and intrauterine pregnancy carried to term. Hum Reprod. 1999;14:1372-4

12. Zeck W, Kelters I, Winter R, Lang U, Petru E. Lessons learned from four advanced abdominal pregnancies at an East African Health Center. J. Perinat Med. 2007;35(4):278-81.

13. Ayinde OA, Aimakhu CO, Adeyanju OA, Omigbodun AO. Abdominal pregnancy at the University College Hospital, Ibadan: a ten-year review. Afr J Reprod Health. 2005;9(1):123-7. 
14. Worley KC, Hnat MD, Cunningham FG. Advanced extrauterine pregnancy diagnostic and therapeutic challenges. Am J Obstetrics Gynecol. 2008;198(3):297.e1-7.

15. Stemens CA. Malformations and deformations in Abdominal pregnancy: Am J Med. 1993;47(8):118995 .
16. Cunningham GF, Levine, KJ, Bloom, SI. Williams Obstetrics. 22nd edition, Prentice Hall International (UK), 2005:265-266.

17. Bertrand G, Le Ray C, Simard-Emond L, Dubois J, Leduc L. Imaging in the management of abdominal pregnancy: A case report and review of literature. J Obstet Gynecol Can: JOGC. 2009;31(1):57-62.

Cite this article as: Trivedi K, Singh L. Advanced abdominal pregnancy with a healthy newborn: a rare case report. Int J Reprod Contracept Obstet Gynecol 2016;5:3583-6. 